are to be looked for in those centres or in the fibres connecting them with each other or with the motor centres in the bulb, or in these motor centres themselves. Such a scheme leaves no necessity for the "propositionising centre" formulated by Broadbent and those who think with him, and on this Dr. Bastian firmly insists. This is not the place to discuss the pros and cons of the two theories. Suffice it to say that in the work before us the author's view is clearly enunciated and is supported by a coherent, closely reasoned argument which will no doubt carry conviction to many. But besides this main theme the numerous and interesting subsidiary problems are most clearly discussed and elucidated, and we congratulate the author on this the crowning edifice of his brilliant and philosophical labours on the subject of speech.

On Maternal Syphilis, inoluding the Presence and Recognition of Syphilitic Pelvic Disease in Women. By John A. ShaW-MACKENZIE, M.D. Lond. London: J. and A. Churchill. 1898. 8vo, pp. 223 . Price 8s. 6d.

THE etiology of the numerous forms of pelvic inflammation to which women are liable was for many years very obscure, but it was gradually proved that in many cases the inflammation was due to the extension locally of a gonorrhoeal vaginitis or endometritis; in many other cases the condition results from some form of septic infection occurring especially in connexion with parturition; but it cannot be said that these two causes will account satisfactorily for all the cases of pelvic disease. The author of this volume is of opinion that in no small proportion of the cases pelvic inflammation is syphilitic in origin. Frequently no history can be obtained of any primary sore, but it is not always easy to find a chancre in women even when it is present, and therefore it is not surprising that no account can be obtained of the presence of such a lesion when several years have elapsed since the time when it probably appeared. In some cases, as Dr. Shaw-Mackenzie shows, undoubted secondary signs may follow a vaginal discharge which was considered to be gonorrhœal in origin. In other cases, again, the author thinks that the syphilis may not have been acquired, but was hereditary in origin. The results of treatment certainly support in many instances the contention that pelvic troubles are due to syphilis. All who see much of syphilis must have met with numerous cases in which lesions certainly syphilitic occur and yet no trace of any syphilitic history is obtainable. Dr. ShawMackenzie is also of opinion that through a mother suffering from inherited syphilis the disease may be transmitted to a third generation. It is very difficult to prove this proposition, but he adduces many cases which certainly afford it some support. In the treatment of the obscure cases of syphilis with which this work deals the author attaches most value to fumigation and inunction.

The whole subject is difficult, but we think that Dr. ShawMackenzie has done much by the publication of this work to clear up some of the difficulties which it presents.

Text-7,ook of Zoology. By H. G. WILLS, B.Se. Lond., and A. M. Daries, B.Sc. Lond. London: W. B. Clive. 1898. Pp. 366. Price 6s. $6 d$.

THIS work is the first of a series, to be soon followed by a text-book of Botany, intended to minister to the wants of students preparing for the intermediate science and preliminary scientific examination of the University of London and other similar tests. The method adopted by the authors is that of the selection of certain types beginning with the rabbit, to which more than a third of the book is devoted, which are carefully worked out. The other types of the vertebrata selected are the frog, dogfish, and lancelet, and of the invertebrata the paramocium, polype, earthworm, anodonta, and crayfish, which are given in less detail
There is a very good chapter on Development. The book is not intended, and should not be used, as a mere cram-book, but the student should rear it with the specimens before him ; if this be diligently practised, he will obtain a good idea of some of the principal groups of the animal kingdom. Questions which have been asked, or are likely to be asked, are appended to each chapter, and we must add a word of praise for the many clear and excellent woodcuts illustrating the text, the drawings for which have been prepared by Mrs. Davies.

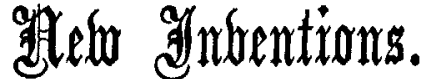

\section{NEW URETHRAL SYRINGE.}

A t my suggestion Messrs. Arnold and Sons, London, have made a urethral syringe which is a modification of one made by them for me and described in THE LANCET of Oct. 17th,

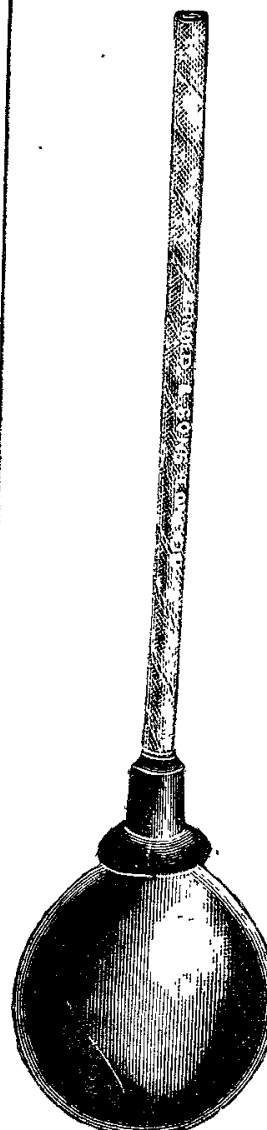
1896. To repeat, the syringe consists of a reservoir to hold $2 \mathrm{oz}$. with a pipe $5 \frac{1}{2}$ in. in length, size No. 8 or 9 catheter. The previous syringe had the pipe channelled on the exterior to allow of the free return of the injection; I find this channelling can be dispensed with if my instructions for using the syringe are carefully carried out, which are as follows. The syringe being filled in the usual manner the pipe is to be dipped in carbolic oil ; now, gently insinuating the nozzle into the meatus by a rotatory motion, the pipe is made to glide slowly in to its full length. No pressure is to be made on the penis, which is allowed to lie in the hand. The reservoir is to be slowly compressed and the injection will be found to return back by the side of the pipe. To the many advantages which I claimed for the syringe in the treatment of gonorrhœea over other syringes I may add another-viz., that the passage of a pipe $5 \frac{1}{2}$ in. in length and stated diameter tends to prevent the possibility of stricture in the spongy portion. This syringe will be found much cheaper in price than my previous instrument and less formidable to a nervous patient. I have prescribed this form of syringe for the last ten years in the treatment of gonorrhoea and my having found it most efficacious is my reason for bringing it under the notice of the profession.

Gloucester-terrace, S.W.

$$
\text { RalPh Stoney, L.R.C.S. Irel., \&c. }
$$

\section{NEW DRESSING TRAY.}

THE accompanying illustration represents a useful kidneyshaped tray for receiving the washings during uterine or vaginal douching and conveying it through rubber tubing to a pail beside the bed or operating table. The spout forms the handle which is curved so as to allow it to be easily held

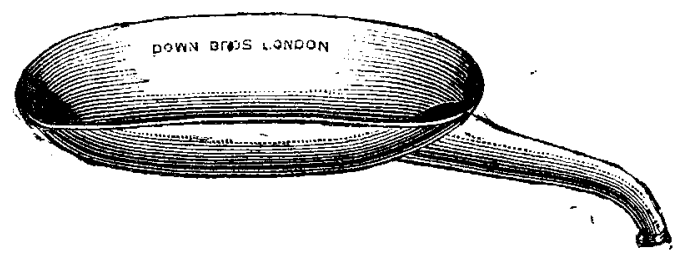

in one hand close to the buttocks without bringing the patient over the edge of the bed. By using this tray, which can be carried in the obstetrical bag, the operator can avoid soiling his hands or the bed. It will also be found useful in syringing ears or douching wounds. It is manufactured by Messrs. Down Brothers, of St. Thomas's-street, London, S.E.

Ealing. ${ }^{\circ} W$.
STRANGMAN GRUBB 
The princely present of the Reverend SAMruel Ashrow THompson-YATES to the College of furnished and equipped

\section{THE LANCET.}

\section{IONDON: SATURDAY, OCTOBER 15, 1898.}

THE city of Liverpool kept Saturday last, Oct. 8th, as a gala day, the occasion being the opening of the new Thompson-Yates Laboratories of Physiology and Pathology by Lord LISTER and the conferring upon him at the same time of the degree of Doctor of Science of the Victoria University. We give in another column a report of the proceedings, but no mere account of what happened, of speeches which were delivered, or of addresses which were read, conveys any idea of the enthusiasm of the people of Liverpool over these two events. The city identified itself with each function in the closest manner. Within the walls of St. George's Hall crowds watched the ceremony which added to the long list of scientific titles enjoyed by the President of the Royal Society the title of Doctor of Science of the Victoria University; without the hall crowds lined the streets, taking the greatest possible interest in the arrival and departure of the distinguished guests of the University College of Liverpool-guests many of whose names are a synonym for learning all over the world; in the Town Hall the Lord Mayor entertained those who had assembled in honour of the occasion with the heartiest of civic welcomes; and every house where the numerous visitors were billeted was the scene of luncheons, dinners, and friendly receptions. What does all this connote? It is certain that if any university, from the most ancient to the most modern of the seats of learning in the kingdom, had five-and-twenty years ago out of its own resources or out of private munificence made some addition to its teaching facilities not a small fraction of the cordial excitement which prevailed last week in Liverpool would have been aroused. A few persons professionally interested in education would have attended the ceremony ; a few citizens, struggling against the feeling that the donor might have made a more practical use of his wealth, would also have been present; and the enthusiasm of the community would have been level with that aroused by, say, the election of an alderman or the gift to the populace of a new drinking-fountain.

Only two weeks ago we referred in a leading article to the tendency towards a fusion of interests between the university and the city in which it is placed as forming one of the most significant as well as one of the most recent developments of modern education, and now we have in Liverpool a remarkable illustration of this spirit of sympathy. University College, Liverpool, has received from Liverpool the sum of $£ 400,000$ or thereabouts during its comparatively short life. This great sum has been given ungrudgingly and established at once a bond beween the College and the city, but the sentiments of gratitude on the one hand and of satisfied generosity on the other will not account for all the mutual goodwill expressed at Liverpool. laboratories for the study of physiology and pathology cost him no less than $£ 28,000$, and Liverpool, or, rather, all England, may well be proud of this open-handed citizen, as the University College has a right to be proud of such a signal and munificent mark of confidence in its work and belief in its future. But the words of Mr. R. B. Haldane, M.P., and Professor Mrchatr Foster at the Town-hall in the evening, no less than the appreciation with which those words were received, show that wider sentiments even than these have been at work in Liverpool to evoke the universal enthusiasm manifested. It is clear that to all gathered together for the inauguration ceremony of the THOMPSON-YATES Laboratories the real significance of the occasion was that another and a great step forward in national education and national progress was being taken, that another practical proof was being furnished of a new educational spirit. One more nail-nay, many and strong nails were being driven into the coffin of the old-fashioned university education which inculcated a spirit of aloofness into its disciples, which led to a division of interests between the best workers and the highest thinkers, and which deprived practical men of the counsels of the learned, while it shunted the learned into careers of compulsory sterility. Medical men will experience a feeling of profound gratification at any successful blow which is dealt at such a system, for it is in the modern curriculum of the medical student that all the good in the old theories of elucation is most closely combined with all the good in the new. Let us not be found laughing at the belief cherished by our grandfathers and probably by our fathers that the real man of culture was the man who could write correct Greek verse. The reason for this error is obvious. One of our greatest schoolmasters and most original thinkers, EDWARD Thring, in an essay defending the study of the dead languages, says roundly that no sane person holds himself a poet because he writes good Iambics. But THRING immediately proceeds to show in his own convincing way that the study of Latin and Greek forms the finest mental exercise known to him and the most convenient medium for inculcating into lads the virtues of industry and accuracy. He acknowledges that but few of the many who read classical literature ever arrive at any real comprehension of its supreme excellence; but, while revering this literature himself as consisting of consummate masterpieces of artistic skill and beauty of form, he treats the study of it simply as means to the end and not as the end itself. This is what the older university men were, so many of them, unable to do, and as a consequence that most stupid article, the man who thought that a first-class university degree would stamp him as a first-class man for the rest of his life, was produced by them in considerable quantities. The real ability of such men was lost to the nation, while in places where learned guidance would have been most valuable the guides were wanting.

Now the modern education of the medical man forms a close link between the old and the new theories of education. It is an education which is living and progressive, which in its higher degrees produces men of indisputable learning and culture, and which is none the less utilitarian. The 